\title{
FLT3 NP_004110.2:p.Y842C
}

National Cancer Institute

\section{Source}

National Cancer Institute. FLT3 NP 004110.2:p.Y842C. NCI Thesaurus. Code C142090.

A change in the amino acid residue at position 842 in the receptor-type tyrosine-protein kinase FLT3 protein where tyrosine has been replaced by cysteine. 